\title{
Efficient Bargaining and the Skill-Structure of Wages and Employment ${ }^{\S}$
}

\author{
by \\ Ulrich Kaiser* and Winfried Pohlmeier**
}

August 2000

\begin{abstract}
This paper presents structural estimates for a bargaining model which nests the right-to-manage, the efficient wage bargaining, the seniority and the standard neoclassical labor demand model as special cases. In contrast to most existing models, our approach accounts for heterogeneous skill groups which differ in terms of productivity and representation in the bargaining process through union preferences. The paper introduces the concept of 'virtual' firms which allows us to (i) test the efficient contract model against models implying that firms operate on the labor demand curve and to (i) ov ercomea potential misspecification of firms' output markets.

Estimates of structural parameters are obtained from a novel cross-section of German firms of the business related service sector which includes information on skill-specific wage rates at the firm lev el. Central results of this paper are that unions do care about both wages and employment in the bargaining process and that firms operate on the contract curve. The bargaining power of unions in East Germany turns out to be muc $\mathrm{h}$ weaker than in West Germany .
\end{abstract}

JEL classification: $L 8, C 22, C 25, G 10$

Keywords: efficient bargaining, skill-structure of employment, business-related services, GMM

\footnotetext{
§This paper ow es nuch to the ZEW's Mannheim Innov ation panel team - namely to Günther Ebling, Sandra Gottschalk, Norbert Janz and Hiltrud Niggemann - for their ongoing effort to create the data set used in this paper, and to Jürgen Moka for maintaining the ZEW's basic data bases. Nadine Warmuth pro videdexcellent research assistance. Both authors gratefully acknowledge funding from the German Science F oundation(DFG) within the 'Industrial Economics and Input Markets' program. The second author also acknowledges financial support by the Center for Finance and Econometrics at the Universit y of Konstanz (CoFE).

${ }^{*}$ Center for European Economic Research, Dep. of Industrial Economics and International Management, P.O.Box 103443, D-68161 Mannheim, Germany, email: kaiser@zew.de; and CoFE.

${ }^{* *}$ Corresponding author: University of Konstanz, Dep. of Economics, D-78457 Konstanz, Germany, email: winfried.pohlmeier@uni-konstanz.de; and CoFE.
} 


\section{Introduction}

Germany's most challenging economic policy problem today is its high rate of unemployment. While a number of European countries such as Denmark, The Netherlands and the United Kingdom have been successful in reducing their unemployment figures to rates of 4-6 percent, the proportion of jobless workers has steadily risen in Germany to over ten percent. As Freeman (1995) writes, the decline in relative demand for low skilled labor has shown up in falling real wages for the less educated in the U.S. whereas in Europe, it appeared as increased unemployment levels of the low skilled. In fact, a fairly broad consensus among economists and policy makers is that the German labor market is too inflexible to substantially reduce unemployment rates. ${ }^{1}$ Consequently, interest in the institutional settings of the German wage bargaining process has recently been revived.

This paper aims at shedding more light on wage setting mechanisms in Germany and on the effects of new technology on the demand for heterogeneous labor. It provides structural econometric evidence on the parameters of the bargaining process. In particular, we are interested in finding econometric evidence for the presence of efficient wage contracts and in quantifying the extent to which workers are willing to reduce wage claims in favor of higher employment. The approach we adopt here is to introduce a general theoretical framework which can be applied as the basis for a structural econometric approach. Since we incorporate the wage bargaining model within a labor demand system, our approach also allows us to analyze the effects of technological change on the demand for heterogeneous labor. The framework we develop encompasses a number of popular labor market models such as the right-to-manage model (Manning, 1987), Oswald's (1993) seniority model, the efficient bargaining model (McDonald and Solow, 1981) and the standard neoclassical labor demand function. Although derived from an efficient bargaining framework as the most general model, our econometric specification nests alternative labor market models which imply that labor is employed along the labor demand curve. The approach allows us to identify the parameters of the unions' preference function with respect to wages and employment. By testing whether wages diverge from their marginal revenue products if unions bargain over both wages and employment, our methodolgy is in the tradition of earlier structural approaches such as that of Brown and Ashenfelter (1986), MaCurdy and Pencavel (1986) and Martinello (1989) for the US, of Bughin (1993) for Belgium and of Pencavel and Holmlund (1988) for Sweden. We introduce the concept of a 'virtual firm' which operates in a competitive environment with prices equal to the actual output and input prices adjusted for market imperfections. This reveals two desirable properties: First, as pointed out by Bughin (1996), product market power significantly erodes wage rents. Hence, an incorrect specification of the output market structure is

\footnotetext{
${ }^{1}$ See Layard and Nickell (1999) for a critical appraisal of alternative institutional labor market settings and detailed descriptive evidence on international labor markets.
} 
likely to lead to serious misspecification of the bargaining mechanism. By conditioning on output and estimating skill-specific virtual labor demand functions with prices are adjusted for market imperfections, our approach is not subject to this specification problem and allows to estimate the relevant parameters of the bargaining process without imposing strong identifying restrictions on the true nature of the bargaining mechanism. Second, our approach allows to choose from a variety of flexible functional forms in order to capture the substitutabilities between skill groups at the firm-level accurately and to assess the differences in the ability to capture economic rents from the bargaining process that arise from differences in technological opportunities.

Our empirical study is based on a cross-section of 696 German firms belonging to the business-related service sector. From an empirical point of view the data set used is of particular interest since it enables the inclusion of skill-specific wages at the firm-level so that substantial variation of wages across skill groups, a property many longitudinal studies at the sectoral level are lacking of, are guaranteed. Moreover, the business-related service sector is of particular interest for three main reasons: first, business-related services belong to the fastest growing sectors of the German economy. The number of employees in business-related services has grown by 29.3 percent between 1982 and 1996 . In comparison, total employment in manufacturing has decreased by 10.7 percent in the same time period. ${ }^{2}$ This economic upturn did, however, not improve the relative position of low skilled labor, as Kaiser (2000a) demonstrates. Second, the business-related services sector is a sector with a low degree of unionization, ${ }^{3}$ its labor market can be regarded as a front-runner in the tendency towards a less centralized bargaining. ${ }^{4}$

Since the contribution by Calmfors and Driffill (1988), it has often been argued that the employment performance of decentralized wage bargaining systems is superior to medium centralized systems with bargaining at the sector and regional level. ${ }^{5}$ This position was recently challenged by Fitzenberger and Franz (1999), who point out that sector-level wage bargaining may well result in a higher average steady state employment if insideroutsider mechanisms are taken into account. Due to its role as a front-runner towards a labor market with less centralized bargaining, a study focussing on the business-related services sector may yield valuable insights into the German labor market of the future and presumably also into the future labor market of other developed countries.

Third, the business-related services sector has experienced substantial investment in in-

\footnotetext{
${ }^{2}$ Source: Janz and Licht (1999).

${ }^{3}$ See section 2 for details and also Kaiser and Pfeiffer (2000) for a discussion of collective wage agreements in the business-related services sector.

${ }^{4}$ As a reaction to those low unionization rates, five currently separate trade unions plan to found a single service-sector union called 'ver.di' in spring 2001. Further information on 'ver.di' can be called up on the internet at http://www .verdi-net.de/.

${ }^{5}$ For more recent studies reaching the same conclusion for Germany, see Berthold and Fehn (1996) as well as Siebert (1997).
} 
formation and communication technologies (IT). Evidence on substitution effects between low skilled labor and IT is scarce for the service sector. The only firm-level study we are aware of is Kaiser (2000b), who shows that skill-biased technological change is present in the German business-related services sector. His model, however, ignores bargaining issues. This drawback is overcome in this paper.

Our wage bargaining model extends the McDonald and Solow (1981) approach by introducing heterogeneous labor so that the unions' preferences concerning wages and employment are allowed to differ across skill groups. In the sequel, we shall argue that although bargaining at the firm-level is not formally institutionalized in the German businessrelated services sector, a bargaining framework at the firm-level may nevertheless serve as a reasonable approximation to analyze the wage setting mechanism in this sector. The validity of collective wage agreements in the German business-related services sector is low. Even for workers employed by firms which are organized in employers' associations, negotiated sectoral wages are often not binding so that actual firm-level wages may lie above or below the wage rates negotiated at the sectoral level. This phenomenon is particularly pronounced in East Germany where 14 percent of the covered firms deviate from collective wage settlements and agree on firm-level arrangements which fix wages below the level negotiated at the sectoral level with their works councils in order to maintain economic survival (see Bellmann et al., 1998 and Scheremet, 1995). Instead of bargaining over wages at the sectoral level, business-related service firms bargain over wages and possibly over employment with work councils or the individual worker.

Empirical evidence on the functioning of the German wage setting mechanism is scarce in general. Carruth and Schnabel (1993) study the determination of contract wages at the macro-level using cointegrating regressions. Their findings support the view that unions do care about employment in the wage bargaining process. Moreover, the authors hypothesize that wage growth can be attributed to powerful work councils at the firm level in the sense that bargaining at the sectoral level can only explain a small fraction of wage growth. Fitzenberger (1999) presents a structural model of wage bargaining for different skill groups. Using sectoral panel data for German manufacturing and non-manufacturing industries, he presents estimates of the structural parameters of a monopoly union model. For manufacturing, his study confirms that decision makers care about changes and not about levels of average wages and employment while the empirical evidence for non-manufacturing is less clear. ${ }^{6}$ Klotz et. al (1999) present a semi-structural right-to-manage model for three skill groups which is estimated for four two-digit sectors using German data. Their study shows that the impact of the technical

\footnotetext{
${ }^{6}$ This somewhat unsatisfactory result is likely to be attributable to Fitzenberger's (1999) inadequate definition of services as 'non-manufacturing' which includes, besides business-related services, gross and retail trade as well as banking and insurance and hence covers very heterogeneous sectors in terms of skill-mix, technology and output.
} 
progress on the skill structure of wages is severely affected by the wage bargaining mechanism. To our knowledge, there is no structural evidence for Germany on the relevance of efficient bargaining over wages and employment.

A central finding of our paper is that workers do care about employment when negotiating oveer wages. We only find a weakly significant difference between the employment goals of East and West German workers. There is, however, a substantial difference in the bargaining power of East and West German employees. In East Germany, employment and wages are, compared to West Germany, to a larger extent determined by the employers. Moreover, we find that the wage goals of workers' differ by skill group and industry. In line with the findings of Kaiser (2000b), our results also indicate weak evidence for the presence of skill-biased technological change in the German business-related services sector.

The outline of the paper is as follows. Section 2 presents some stylized facts of the business-related services sector and the structure of its labor market. In Section 3 we derive our structural econometric model from the efficient bargaining framework. In Section 4 information on our data source is provided. In Section 5 we display and discuss estimation results. Section 6 concludes and gives an outlook on future research.

\section{Wage setting in the service sector: stylized facts}

No other sector of the German economy has developed so emphatically over the past ten years as has the business-related services sector. Total employment in the businessrelated services sector has increased by 59.6 percent in West Germany between 1982 and 1996. In comparison, total employment in manufacturing industries has decreased by 10.8 percent in the same period. ${ }^{7}$ The share of business-related services in West Germany's total employment has grown from 6.9 percent in 1982 to 9.9 percent in 1996. At the same time, the share of manufacturing industries in total employment has decreased from 42.9 in 1982 to 34.3 percent in $1996 .^{8}$

Clearly, much of the growth of the business-related services sector and the contraction of the manufacturing sector is attributable to increased outsourcing activities of manufacturing industries in the '90s. However, the statistical recording of the service sector in general and especially of business-related services is still somewhat inversely related

\footnotetext{
${ }^{7}$ Source: Own calculations based on data provided to the ZEW by the Institute for Employment Research (Institut für Arbeitsmarkt- und Berufsforschung, IAB).

${ }^{8}$ Following Miles (1993), we define business-related services by enumeration of the following sectors: management consultancy, tax consultancy, architectural and engineering activities, sewage and refuse disposal, cargo handling and storage, computer and related activities, advertising, real estate, machine and vehicle renting, industrial cleaning, labor recruiting and private investigation.
} 
Table 1: Share of Firms Applying Collective Wage Agreements (as percentage of total sales)

Business-related services (SSBS, 1999): as percentage of total sales

\begin{tabular}{|c|c|}
\hline & sales share \\
\hline Computer \& related activities & 29.7 \\
\hline Tax consultancy & 4.5 \\
\hline Management consultancy & 22.3 \\
\hline Architectural activities & 25.8 \\
\hline Techn. consultancy & 41.1 \\
\hline Advertising & 13.4 \\
\hline Vehicle rental & 37.2 \\
\hline Machine rental & 16.2 \\
\hline Cargo handling & 73.6 \\
\hline Sewage disposal & 74.0 \\
\hline Business-related services (total) & 37.9 \\
\hline Business-related services (East Germany) & 37.9 \\
\hline Business-related services (West Germany) & 37.9 \\
\hline \multicolumn{2}{|c|}{ Selected sectors (Bispinck, 1999): as percentage of total employment } \\
\hline \multicolumn{2}{|r|}{ employment share } \\
\hline & West Germany East Germany \\
\hline Total & 50.5 \\
\hline Other services & 45.6 \\
\hline
\end{tabular}

to its growing overall economic importance. As a consequence, empirical studies on the German service sector are scarce. In particular, not much is known about wage setting in business-related services. Besides the lack of appropriate data, wage negotiations in business-related services proceed in an entirely different way to those in manufacturing industries. Using data taken from the 'Service Sector Business Survey' (SSBS), a quarterly business survey in ten branches of the business-related services sector which is collected by the ZEW in cooperation with Germany's largest credit rating agency Creditreform, ${ }^{9}$ Kaiser and Pfeiffer (2000) find that only 38 percent of total sales in the business-related services sector are realized by firms bound to collective wage agreements. Table 1 displays the importance of collective wage agreements across the different sectors surveyed in the SSBS. ${ }^{10}$ Differences between East and West Germany with respect to the validity

\footnotetext{
${ }^{9} \mathrm{~A}$ more thorough description of this data is given in Kaiser et al. (2000).

${ }^{10}$ Note that all values are expanded using sales expansion factors as described in Kaiser et al. (2000).
} 
Table 2: Shares of Different Skill Groups in Total Employment of Business-Related Services and Manufacturing Industries

\begin{tabular}{|c|c|c|c|c|c|}
\hline Sector & unskilled & $\begin{array}{c}\text { vocational } \\
\text { training } \\
\end{array}$ & $\begin{array}{c}\text { technical } \\
\text { training } \\
\end{array}$ & $\begin{array}{c}\text { technical } \\
\text { college }\end{array}$ & university \\
\hline \multicolumn{6}{|l|}{ Manufacturing } \\
\hline West Germany & 15.9 & 61.4 & 10.6 & 4.8 & 3.9 \\
\hline East Germany & 2.6 & 71.7 & 9.8 & 4.4 & 7.0 \\
\hline \multicolumn{6}{|c|}{ Business-related services } \\
\hline West Germany & 6.8 & 49.8 & 7.3 & 12.0 & 21.2 \\
\hline East Germany & 2.8 & 53.7 & 6.2 & 8.1 & 25.8 \\
\hline
\end{tabular}

of collective wage agreements do not exist, as shown in Table 1. This is in contrast to the figures for the entire German economy, as becomes visible in the lower part of Table 1 and also holds if it is controlled for firm size, skill structure and sector affiliation as shown in Kaiser and Pfeiffer (2000). For reasons of comparison, Table 1 also contains the coverage of employees in collective wage agreement as calculated by Bispinck (1999, p. 10). ${ }^{11}$ According to these figures, collective wage agreements cover 67.8 percent of the West German employees and 50.5 percent of the East Germany employees. In the service sector, the overall coverage is 55.2 percent for West Germany and 45.6 percent for East Germany. The SSBS-figures and Bispick's data are not directly comparable since the SSBS figures are related to sales while Bispick's figures are related to the number of employees. Nevertheless, it is indicated that the diffusion of collective wage agreements is lower in the service sector than in the total economy. It is even lower in the fast growing business-related services sector.

With respect to the SSBS-figures, there are considerable differences within the businessrelated service sector. E.g., the reason for the above-average validity of collective wage agreements in transport and storage as well as in sewage and refuse disposal as displayed in Table 1 is that explicit collective wage agreements do exist for these sectors. One of the main reasons for the minor importance of collective wage agreements across businessrelated services is simply that often no collective wage contracts are available. ${ }^{12}$ A second reason is that the skill structure in business-related services differs considerably from that

\footnotetext{
${ }^{11}$ Also see Bellmann et al. (1999).

${ }^{12}$ Note that this does not imply that firms from these sectors never apply collective wage agreements since they are allowed to adopt collective wage agreements of other sectors. Due to the fact that many of the business-related services firms are outsourced by manufacturing industries, it is likely that they simply adopted their mother company's wage contracts (for more details see Kaiser and Pfeiffer, 2000).
} 
of manufacturing industries, as shown in Table $2 .{ }^{13}$ Employees tend to be higher qualified in business-related services than in manufacturing. In particular, there is a considerably larger number of university graduates in business-related services than in manufacturing which, as Fitzenberger et al. (1999) have shown, goes along with lower unionization rates. These results are supported by Kaiser and Pfeiffer (2000) for the German business-related services sector.

\section{An Econometric Bargaining Model}

The model from which we derive our structural estimation equations rests upon a conventional bargaining framework in the tradition of McDonald and Solow's (1981) efficient bargaining model. We extend the standard static model by introducing multiple skill groups whose wage preferences are allowed to differ since there ex ante is no convincing reason to assume that workers across all skill groups pursue the same wage and employment goals. In fact, experience from the recent wage bargaining rounds in various sectors of the German manufacturing industry supports the view that workersbargain for stronger wage increases for the low skilled than for the high skilled workers. On the one hand, high skilled workers are more likely to take on managerial responsibilities leading to a looser link to the unions' goals which is reflected in the lower share of union membership among high skilled workers. ${ }^{14}$ On the other hand, one might argue that high skilled workers might more effectively intersperse their goals in a wage bargaining process.

Let us assume that firms employ workers belonging to $n$ different skill groups and let $L_{i}$ denote the labor input of skill level $i$. Output $y$ is produced according to the production function $y=f\left(L_{1}, \ldots, L_{n}, x\right)$ with $x$ being a quasi-fixed production factor. IT-capital, proxied by IT-investment, is treated as a quasi-fixed factor. This appears to be useful since new technologies are often named as a typical example for technical progress, especially for services. ${ }^{15}$ The firm is assumed to be profit-maximizing and to be facing a downward-sloping inverse product demand function $p(y)$. Hence, short-run profits are given by $\pi\left(w_{1}, \ldots, w_{n}, L_{1}, \ldots, L_{n}, x\right)$. Wages and employment levels of the different skill groups are assumed to be determined by the following Nash bargaining:

$$
\max _{w_{1}, \ldots, w_{n}, L_{1}, \ldots, L_{n}} U\left(w_{1}, \ldots, w_{n}, L_{1}, \ldots, L_{n}\right)^{\theta} \pi\left(w_{1}, \ldots, w_{n}, L_{1}, \ldots, L_{n}, x\right)^{1-\theta},
$$

where $\theta$ reflects workers' bargaining power. The first-order conditions in terms of elasticities are given by:

$$
\eta\left(U, L_{i}\right)=-\frac{1-\theta}{\theta} \eta\left(\pi, L_{i}\right)
$$

${ }^{13}$ The source of Table 2 is Pfeiffer and Falk (1999), Tables $3-3$ and $3-4$.

${ }^{14}$ See Fitzenberger et al. (1999) for German evidence on this issue.

${ }^{15}$ See Kaiser (2000b) for a more thorough discussion on proxy variablesfor technical progress. 
and

$$
\eta\left(U, w_{i}\right)=-\frac{1-\theta}{\theta} \eta\left(\pi, w_{i}\right)
$$

Division of (3.2) by (3.3) leads to an efficient contract curve which is the locus where the unions' indifference curves are tangent to the firms' isoprofit curves:

$$
h_{i} \equiv \frac{\eta\left(U, L_{i}\right)}{\eta\left(U, w_{i}\right)}=\frac{\eta\left(\pi, L_{i}\right)}{\eta\left(\pi, w_{i}\right)},
$$

In models involving homogeneous labor only, the term $h$ is often called "the absolute value of the elasticity of the wage with respect to employment along the union's indifference curve" (e.g. Bean and Turnbull, 1988). This formulation of the first order conditions of efficient wage bargaining nicely reveals that $h_{i}$ captures the additional employment effect that arises from bargaining over employment such that the marginal revenue of labor input $i$ is smaller than the wage rate. Therefore, a natural way to discriminate between models which imply employment on the contract curve from models which imply employment on the labor demand curve is to test for the presence of a positive $h_{i}$.

Since $\partial \pi / \partial L_{i}=p(1-m) f_{i}-w_{i}$ and $\partial \pi / \partial w_{i}=-L_{i}$, equation (3.4) can be expressed by:

$$
p(1-m) f_{i}=\left(1-h_{i}\right) w_{i}, \quad(i=1, \ldots, n),
$$

where $m$ is the usual absolute value of the inverse of the price elasticity of demand.

\section{Virtual Demand Functions}

The key idea of our econometric approach rests upon exploiting the information given by equation (3.5) in a novel way. Since only skill-specific wages and labor input combinations - and not the contract curve as a whole - are observable for each firm, the first order conditions as shown above can be locally treated as the first order conditions of a profit maximizing firm with the same technology operating in a competitive labor market with virtual wages $\tilde{w}_{i}=\left(1-h_{i}\right) w_{i}$, output prices $\tilde{p}=(1-m) p$ and Marshallian labor demands $L_{i}=L_{i}\left(\tilde{w}_{1}, \ldots \tilde{w}_{n}, \tilde{p}, x\right)$. Thus a virtual firm can be defined as a neoclassical firm operating at the same factor demand levels as the true firm under consideration but facing virtual prices that are equivalent to the actual prices adjusted for the market imperfections.

This idea is graphically depicted in Figure 1 for the case of two labor inputs. The isoquant is tagent to the isocost-curve in the $L_{1}-L_{2}$-space. Due to market imperfections, the true 


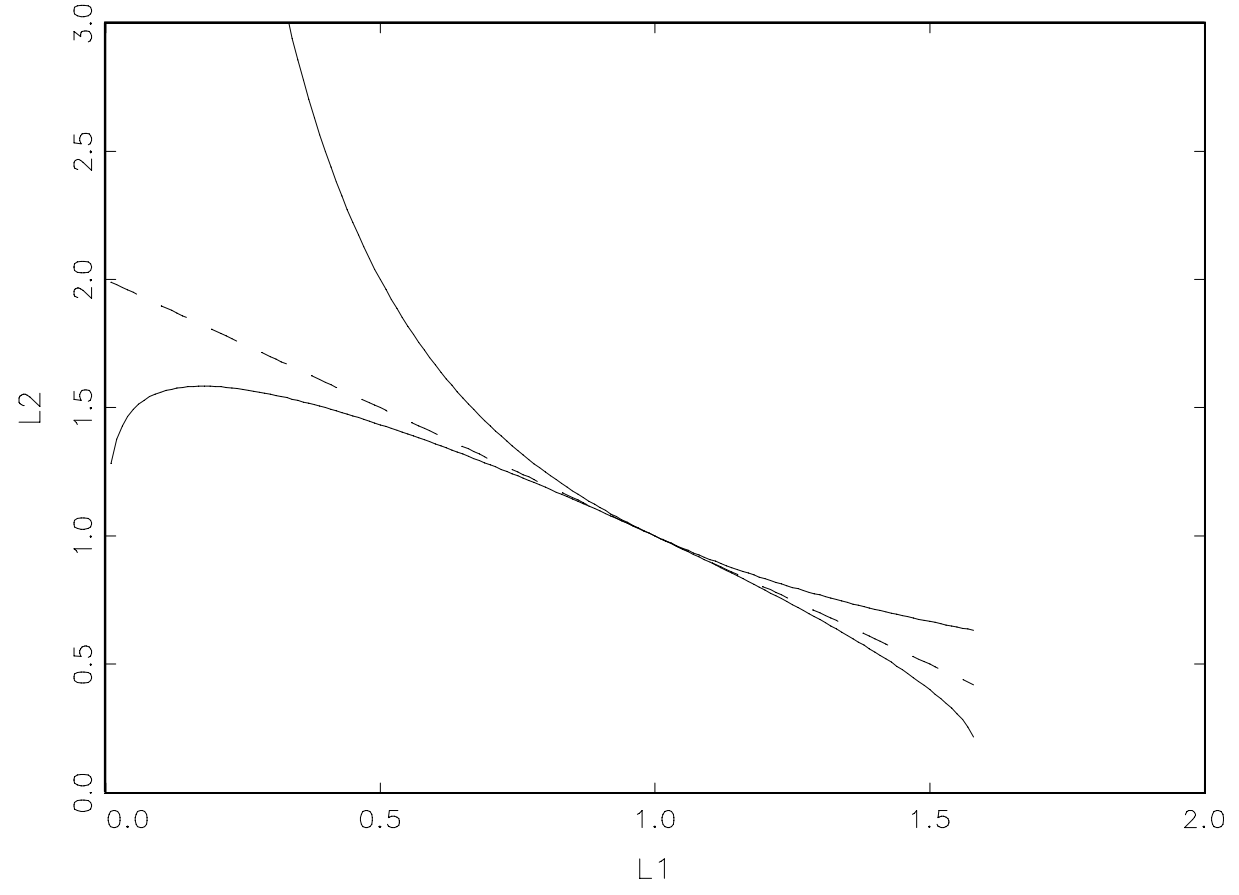

Figure 1: Optimal Skill Structure

isocost-curve is nonlinear because of the endogeneity of wages. The actual factor inputs can, however, be locally described by the linear isocost-curve (dashed line) of the virtual firm. By virtue of duality, the corresponding conditional labor demand functions of a firm are given by:

$$
L_{i}=L_{i}\left(\tilde{w}_{1}, \ldots, \tilde{w}_{n}, y, x\right) \quad(i=1, \ldots, n) .
$$

Rewriting the labor demand equations of the virtual firm in terms of conditional factor demands allows us to choose from a variety of flexible functional forms which are sufficiently flexible to generate insights into the substitutability of the skill groups. Instead of choosing the more standard translog functional form, we decide to take the Generalized Leontief (GL) factor demands system with quasi-fixed factors (Morrison, 1988). A main advantage of the GL function over the translog functional form is that it provides a richer framework for analyzing substitution patterns between the quasi-fixed factors and the labor inputs. As opposed to the translog factor function, linear-homogeneity holds by construction. Under consideration of the virtual wages, the GL factor demand function for labor of type $i$ is:

$$
L_{i}=y\left(\sum_{j=1}^{n} \alpha_{i j} \psi_{i j}\left(\frac{w_{j}}{w_{i}}\right)^{1 / 2}\right)+\delta_{i}(x y)^{1 / 2}+\gamma_{i} x,
$$

with: $\quad \psi_{i j}=\left(\frac{1-h_{j}}{1-h_{i}}\right)^{1 / 2}$.

The term $\psi_{i j}$ serves as an adjustment factor for the observed relative wages according to the workers preferences such that the labor inputs of the virtual firm coincide with those of 
the actual firm. In the empirical part of this paper, we discriminate between three types of labor: high skilled workers (university and/or technical college graduates), medium skilled workers (workers with completed vocational) and unskilled workers (workers with no formal qualification).

\section{Preferences}

In order to obtain a functional form for the adjustment factors, we assume the following preference function of the workers:

$$
U=\prod_{i=1}^{n}\left(w_{i}-w_{i}^{*}\right)^{\mu_{i}}\left(\frac{L}{L^{*}}\right)^{\lambda}, \quad \sum_{i=1}^{n} \mu_{i}=1
$$

where $w_{i}^{*}$ represents the outside wage of skill group $i$. For the sake of parsimony, we assume that total employment $L=\sum_{i=1}^{n} L_{i}$ rather than skill-specific employment enters the worker's preference function. The term $L^{*}$ denotes the reference employment level. Outside wages are calculated as follows: under the assumption that workers find a job at the mean wage rate of the respective skill group, $\bar{w}_{i}$, with probability equal to the skillspecific rate of employment or are compensated by unemployment benefits proportional to the wage rate they currently earn, the outside wage is defined by:

$$
\begin{aligned}
w_{i}^{*} & =\left(1-u_{i}\right) \bar{w}_{i}+u_{i} b_{i} \\
& =\left(1-u_{i}\right) \bar{w}_{i}+u_{i} \rho w_{i},
\end{aligned}
$$

where $u_{i}$ is the skill-specific unemployment rate, ${ }^{16} b_{i}$ denotes unemployment benefits and $\rho$ is the replacement ratio. Mean skill-specific wages are constructed as the ten percent percentile of the skill-specific and firm-specific wages from our sample. For the replacement ratio, we assume a value of $\rho=0.65$.

Since relative employment and not the difference between actual and reference employment is assumed to determine the union's utility, the preference function becomes weakly separable on the reference employment level. A brief look at the first order conditions (3.2) and (3.3) reveals that, in this case, the efficient contract is independent of the reference employment level.

Summing up the first-order condition w.r.t. wages (equation (3.3)) and using the addingup restriction on the $\mu_{i}^{\prime} s$, leads to a simple relationship between the power parameter $\theta$ and the skill-specific employment and wage levels:

$$
\theta=\frac{\sum_{i}\left(w_{i}-w_{i}^{*}\right) L_{i}}{\pi+\sum_{i}\left(w_{i}-w_{i}^{*}\right) L_{i}}
$$

\footnotetext{
${ }^{16}$ We further distinguish between East and West German unemployment rates in the empirical investigation.
} 
Inserting (3.9) into (3.3) provides a similiar relationship for the skill-specific preference parameters:

$$
\mu_{i}=\frac{\left(w_{i}-w_{i}^{*}\right) L_{i}}{\sum_{i}\left(w_{i}-w_{i}^{*}\right) L_{i}} \quad(i=1, \ldots, n)
$$

For the skill-specific preference function introduced above, $h_{i}$ becomes:

$$
h_{i} \equiv \frac{\lambda \frac{L_{i}}{L}}{\mu_{i} \frac{w_{i}}{w_{i}-w_{i}^{*}}}
$$

Although derived from a scenario with efficient bargaining over wages and employment, our approach nests the right-to-manage model, the seniority model and the standard neoclassical model as special cases. Based on the estimation of the virtual demand functions, a test of $\lambda=0$ implies testing the efficient contract model against the null hypothesis that firms are operating on the contract curve. As pointed out by Martinello (1989), such a test is unable to discriminate between the right-to-manage model and the seniority model since both variants imply wage/employment combinations on the labor demand curve.

\section{Data}

We estimate the parameters of our bargaining model using the Mannheim Innovation Panel in the Service Sector (MIP-S). The MIP-S is a mail survey which is collected by the Center for European Economic Research (ZEW). It is part of the European Commission's Community Innovation Survey (CIS) program. The concept, the design and main empirical findings of the MIP-S are provided by Janz et al. (2000). We base our empirical analysis on the second and up to now most recent wave of the MIP-S which was collected in $1996 .^{17}$

The population of the MIP-S consists of all firms with more than four employees. The MIP-S is a stratified random sample, stratified with respect to sectoral and regional affiliation (East/West Germany) and with respect to firm size classes. The focus of the questionnaire is on innovation issues, though it also includes questions on firms' skill structure, on IT-investment and on labor cost.

The MIP-S is restricted to marketed services only and therefore comprises wholesale and retail trade, transport, traffic, banking, insurance, software, technical consultancy, marketing, and 'other' business-related services. We do not consider banking and insurance or retail and gross trade in the empirical part of this paper since these differ greatly from

\footnotetext{
${ }^{17}$ Public use files are available for both data sets used in this paper. Please write to Norbert Janz at the Center for European Economic Research (janz@zew.de) .
} 
the business-related services sector with respect to wage negotiation, output measurement and economic growth rates.

The empirical implementation of our theoretical model is straightforward: the estimation of the union bargaining power parameter, $\theta$, according to equation (3.9), and the estimation of the importance of the skill-specific preference parameters, $\mu_{i}$, both simply require the calculation of arithmetic means. The weight the employees attach to employment, $\lambda$, is estimated jointly with the parameters of the Generalized Leontief cost function as in equation (3.7). A major problem with the measurement of $\theta$, however, is the measurement of profits, $\pi$, since the MIP-S does not contain information on profits. This is of course a major drawback of the MIP-S data in the present context. It is, however, well known that materials and intermediate products play a much less important role in the service than in the manufacturing sector so that we proxy profits as the difference between total sales and total labor cost. ${ }^{18}$

A major problem associated with survey data usually is that labor cost for different types of labor are not available at the firm level. Kaiser (2000c), however, has shown that it is possible to derive firm-specific and skill-specific labor cost from information on total labor cost, on the skill mix and other observable firm characteristics only. Just as we do, Kaiser (2000c) uses data taken from the MIP-S in his empirical analysis. Straightforwardly, we apply his method to calculate skill-specific and firm-specific labor cost.

\section{Estimation results}

Our empirical analysis begins with the calculation of the union bargaining parameter $\theta$ according to equation (3.9). The parameter $\theta$ can easily be obtained from rewriting equation (3.9) as

$$
\ln \left(\frac{\Pi}{\sum_{i}\left(w_{i}-w_{i}^{*}\right) L_{i}}\right)=\ln \left(\frac{1-\theta}{\theta}\right)
$$

so that estimates for $\theta$ are obtained by running an OLS regression of $\ln \left(\frac{\Pi}{\sum_{i}\left(w_{i}-w_{i}^{*}\right) L_{i}}\right)$ on a constant term, recovering $\theta$ and calculating the related standard error using the 'Delta'-method. Since we are also interested in the differences between East and West

\footnotetext{
${ }^{18}$ Information on the cost structure of the German service sector is available from a number of publications by the German Federal Statistical office: for cargo handling (Statistisches Bundesamt, 1995a), for architecture, engineering, tax consulting (Statistisches Bundesamt, 1995b), for management consulting (Statistisches Bundesamt, 1995c), for recycling and manufacturing (Statistisches Bundesamt, 1995d).
} 
Germany and in inter-sectoral differences, we additionally run such OLS regressions on dummy variables for East and West German firms, leaving out the constant term, and on sector dummy variables interacted with the East and West dummy variables, respectively. Estimation results for the bargaining power parameter $\theta$ are displayed in Table 3. Descriptive statistics of the variables and the instruments used for the regressions are displayed in Table A1 in the Appendix. It is important to note that we - by proxying profits by the difference between total sales and total labor cost - overestimate firms' profits and hence workers' bargaining power.

The estimation results for $\theta$ are based on 960 observations. They indicate that the bargaining power of the workersis considerably smaller than that of the employers. The point estimate of workers' bargaining power is 0.1314 and is estimated with great precision. We find highly significant differences between East and West Germany with respect to union bargaining power. For East Germany the point estimate is 0.0869, for West Germany it is 0.1675 . Both coefficients are estimated with great precision. Due to these differences, we report the parameter estimates for the individual sectors separately for East and West Germany. The remarkable low figures for some East German sectors reveal that labor demand in these sectors can almost be described by monopsonistic behavior. In addition our findings indicate that union bargaining power is large in those sectors with a good economic performance in 1996, such as management and technical consultancy as well as software. This is valid both for East and West Germany, though union bargaining power is significantly larger in West than in East Germany in each of the individual sectors as well.

The empirical findings for the factor demand system (3.7) result from a two-step estimation procedure where we first estimate the wage-specific preference parameters $\mu$ according to equation (3.10). In a second step, we use the estimated $\mu$ 's to compute the adjustment factors for the skill-specific wages in the virtual demand functions. Estimates for the $\mu$ 's are obtained by treating (3.10) as a location parameter model where the estimates result from linear regressions. This allows us to conduct inferences about the size of the coefficients across the different subsectors of the business-related services sector by including sector-specific dummy variables.

In the first panel of Table 4 we display the regression results for the $\mu$ 's, as calculated according to equation (3.10), on seven sector dummies, leaving out a constant term. The second panel of the table presents aggregate estimates (i) for the entire sector and (ii) separately for East and West Germany. A total of 1041 observations were involved in the estimation of the $\theta$ 's. Since some of the sectors listed in section 2 contain very few observations, we decided to use the following sector dummy variables: CONSULTING (Management \& tax consultancy), TECHNICAL (architectural and engineering activities), OTHER BRS (other business-related services: advertising, real estate, machine and vehicle renting), SEWAGE (sewage and refuse disposal), CARGO (cargo handling and storage), SOFTWARE (computer and related activities) OTHER (industrial cleaning, labor recruiting and private investigation). 
Table 3: Estimation results for $\theta$

Coeff. Std. err.

\begin{tabular}{lrrrr}
\hline \hline Germany & & 0.1314 & 0.0048 & \\
East Germany & & 0.0869 & 0.0052 & \\
West Germany & & 0.1675 & 0.0071 & \\
\hline & \multicolumn{2}{c}{ West Germany } & \multicolumn{2}{c}{ East Germany } \\
& Coeff. & Std. err. & Coeff. & Std. err. \\
\hline \hline CONSULTING & 0.2574 & 0.0241 & 0.1431 & 0.0271 \\
TECHNICAL & 0.3139 & 0.0293 & 0.1437 & 0.0136 \\
OTHER BRS & 0.0891 & 0.0095 & 0.0471 & 0.0060 \\
SEWAGE & 0.1070 & 0.0168 & 0.0519 & 0.0094 \\
CARGO & 0.1246 & 0.0106 & 0.0747 & 0.0089 \\
SOFTWARE & 0.2099 & 0.0197 & 0.1199 & 0.0217 \\
OTHER & 0.1859 & 0.0195 & 0.0552 & 0.0180
\end{tabular}

Table 4: Estimation results for $\mu$

High skilled Medium skilled Low skilled $\mu_{1} \quad \mu_{2} \quad \mu_{3}$ Coeff. Std. err. Coeff. Std. err. Coeff. Std. err.

\begin{tabular}{lllllll}
\hline \hline CONSULTING & 0.5476 & 0.0311 & 0.4287 & 0.0332 & 0.0238 & 0.0224 \\
TECHNICAL & 0.3137 & 0.0238 & 0.6175 & 0.0255 & 0.0688 & 0.0172 \\
OTHER BRS & 0.1559 & 0.0246 & 0.6927 & 0.0263 & 0.1515 & 0.0177 \\
SEWAGE & 0.2062 & 0.0360 & 0.3589 & 0.0385 & 0.4348 & 0.0260 \\
CARGO & 0.1583 & 0.0213 & 0.5372 & 0.0228 & 0.3045 & 0.0154 \\
SOFTWARE & 0.5306 & 0.0290 & 0.3818 & 0.0310 & 0.0876 & 0.0209 \\
OTHER & 0.2166 & 0.0340 & 0.4476 & 0.0364 & 0.3358 & 0.0245 \\
\hline Germany & 0.2853 & 0.0113 & 0.5252 & 0.0115 & 0.1895 & 0.0085 \\
\hline East Germany & 0.2736 & 0.0181 & 0.5707 & 0.0184 & 0.1556 & 0.0135 \\
West Germany & 0.2928 & 0.0145 & 0.4959 & 0.0147 & 0.2113 & 0.0108
\end{tabular}


The values of the $\mu$ 's reflect the importance the respective skill group possesses in pursuing its wage goal in the bargaining process. The larger the difference between the wage bill of a skill group in comparison to its expected outside wage bill in a specific sector is, the larger the corresponding value of $\mu$ is. To put it differently, skill groups with high $\mu$ 's are those who are able to set their wage bills well above the wage bill they would receive if they accepted the outside opportunity. The $\mu$ 's are estimated with high precision as indicated by the large $t$-values associated with the parameter estimates.

Looking at the aggregate estimates first, we do not find significant differences between East and West Germany for $\mu_{1}$ (high skilled labor). The magnitude of $\mu_{2}$ (medium skilled labor) is significantly larger in East than in West Germany while the reverse is true for $\mu_{3}$ (low skilled labor).

Our estimates clearly indicate that workers' preferences with respect to their wage goals vary across skill groups and sectors. Medium skilled workers are in general the most successful skill group in a bargaining process. This finding is in accordance with median voter behavior. If wage goals of the work force as a whole are mainly determined by the largest skill group, which is medium skilled labor in our context, we expect that this group is best represented in the workers overall preference function.

Although the preference parameter for medium skilled workers is almost of the same size across sectors, we observe large sectoral differences for the preference parameters of the two other skill groups. For sectors with a comparatively large degree of unionization, such as $S E W A G E$ and $C A R G O$, we find large $\mu$ 's for the group of unskilled labor. In contrast, the sector SOFTWARE is the only one in which the wage goal of high skilled labor is nearly as powerfully represented in the preference function as the wage goal of medium skilled labor. This result supports the view that, despite being weakly organized in unions, high skilled labor can effectively bargain over wages at the firm level.

In Table 5 we display GMM estimation results for the Generalized Leontief factor demand system, equation (3.7), with the usual symmetry restrictions being imposed. In order to account for potential differences in the bargaining process between East and West Germany, we present estimates for two different specifications. The first specification assumes that the employment parameter $\lambda$ is the same for East and West Germany, while the second allows for different employment goals in East and West Germany.

Our theoretical model by construction implies that the virtual prices are highly endogenous. We therefore apply a GMM estimation approach. Six sectoral dummy variables (with OTHER serving as the base category), lagged relative factor prices and lagged ratios of the quasi-fixed factor scaled by sales and its square root, as well as lagged export share and lagged innovation intensity (innovation intensity scaled by sales) are used as instruments. ${ }^{19}$ These instruments yield valid orthogonality conditions which cannot be

\footnotetext{
${ }^{19}$ Some questions in the MIP-S questionnaire of 1996 were asked retrospectively for 1995 ,
} 
Table 5: GMM estimation results of equation (3.6)

\begin{tabular}{lcrrr} 
& \multicolumn{2}{c}{ West/East joint } & \multicolumn{2}{c}{ West/East separate } \\
& \multicolumn{1}{c}{ Coeff. } & Std. err. & \multicolumn{1}{c}{ Coeff. } & Std. err. \\
\hline \hline$\alpha_{11}$ & $-5.3824^{* * *}$ & 0.2735 & $-5.1614^{* * *}$ & 0.2872 \\
$\alpha_{12}$ & $4.1134^{* * *}$ & 0.3981 & $2.8018^{* * *}$ & 0.5207 \\
$\alpha_{13}$ & $4.6894^{* * *}$ & 0.3758 & $4.841^{* * *}$ & 0.3878 \\
$\alpha_{22}$ & -1.2538 & 1.0963 & 0.7855 & 1.3312 \\
$\alpha_{23}$ & $-3.4381^{* * *}$ & 0.7626 & $-2.7367^{* * *}$ & 0.8735 \\
$\alpha_{33}$ & $-1.7166^{* *}$ & 0.7348 & $-2.71^{* * *}$ & 0.8479 \\
$\lambda$ & 0.6518 & 0.0705 & & \\
$\lambda_{W e s t}$ & & & $0.3377^{* * *}$ & 0.1295 \\
$\lambda_{\text {East }}$ & & & $0.9183^{* * *}$ & 0.2237 \\
$\delta_{1}$ & $5.4765^{*}$ & 3.2516 & $13.9768^{* * *}$ & 3.369 \\
$\gamma_{1}$ & -0.2156 & 11.1553 & -10.3706 & 10.5252 \\
$\delta_{2}$ & $28.7343^{* * *}$ & 4.2479 & $13.9897^{* * *}$ & 4.6936 \\
$\gamma_{2}$ & $-49.6626^{* * *}$ & 13.2329 & $-25.4714^{* *}$ & 13.1942 \\
$\delta_{3}$ & 1.7114 & 3.3477 & 2.729 & 3.6002 \\
$\gamma_{3}$ & -0.9412 & 7.8108 & -7.9065 & 8.956
\end{tabular}

rejected on the basis of the J-statistics for both specifications. The $\mathrm{p}$-values are 0.3616 and 0.3024 for the parsimonious and the specification with different $\lambda$ 's for East and West Germany, respectively.

Due to missing values, 696 observations are included for the GMM estimation. The estimate for the employment parameter $\lambda$ clearly indicate that employment is taken into account in the bargaining process. The workers' preferences are characterized by downward-sloping indifference curves, i.e. they are willing to accept income reductions in favor of employment increases. Our results are neither obvious nor did we expect these findings: first, the great precision of our estimates indicates that wages and employment are determined on the contract curve rather than on the labor demand curve. This is somewhat in contrast to the more or less mixed evidence presented in earlier structural estimates as those by Brown and Ashenfelter (1986), MaCurdy and Pencavel (1986) and Martinello (1989) for various US industries. Besides the obvious argument that this study analyzes an entirely different labor market, the precision of our estimates clearly gains from the large cross-sectional variation of wages at the firm-level. Second, the risk of becoming unemployed in the booming business-related service sector is comparatively low. Therefore, one could argue along the reasoning of Oswald's (1993) seniority model that the median worker is not at risk of becoming unemployed and thus neglects any meaning that lagged values of these variables could be taken into account. 
employment goals. Our findings clearly reject this view.

A somewhat stronger test of the presence of efficient bargaining is to distinguish between the East German and the West German labor markets. If workers in East Germany are more concerned about the employment goal due to the substantially higher rate of unemployment and if firms and workers bargain more often at the firm-level for wages and employment in East Germany, we expect the $\lambda$-coefficient for East Germany to be larger than the corresponding coefficient for West Germany. Our estimates support this conjecture. Workers in Germany seem to be willing to accept a steeper trade--off between wages and employment. A test of the null hypthesis of equality of the two $\lambda$-coefficients, however, can only be rejected at the 0.0637 marginal significance level.

Finally, our theoretical model suggests that changes in the use of the quasi-fixed factor have an effect both on relative prices and on labor demand, which in turn affect one another. Hence, the coefficients $\delta$ and $\gamma$ can only be interpreted under the ceteris paribus assumption that a change in IT-investment only affects the demand for heterogeneous labor while it leaves relative factor prices unchanged. Under this assumption and using the parameter estimates from the separate estimation of $\lambda$, we find that the mean elasticity of high skilled labor demand with respect to IT-investment is 0.439 ; that of medium skilled labor is 0.017 , and that of low skilled labor is -0.184 . We find that the elasticity for high skilled labor is significantly different from zero while this is not true for the two other elasticities. Given that changes in IT-investment leave the wage structure unchanged, we hence do not find strong evidence for capital-skill complementarities but for capital-skill complementarities.

With respect to the parameters of the relative prices, $\alpha_{i j}$, we find highly significant substitutabilities between high and medium skilled labor as well as between high and low skilled labor. The relationship between medium and low skilled labor is complementary.

\section{Conclusion and suggestions for further research}

In this paper we present a general bargaining model which nests the traditional rightto-manage, the seniority model and the standard neoclassical labor model as special cases. The model is based on the efficient wage bargaining model of McDonald and Solow (1981), which we extend to capture heterogeneous instead of homogeneous labor only. By introducing the concept of 'virtual' firms, our approach allows us to identify the relevant parameters of the bargaining process without imposing any additional assumptions on the firm's output market and the true nature of the bargaining process.

The wage bargaining model is structurally estimated using firm-level data from the fastgrowing German business-related services sector. This sector is especially interesting to 
study since unionization rates in this sector are low. The sector also appears as a frontrunner in the tendency to refrain from the sectoral wage-bargaining system in Germany. Hence, an analysis of this sector leads to valuable insights into the German labor market of tomorrow.

The theoretical model allows us to estimate the weight the different types of heterogeneous labor possess in the worker's association preference function. It is shown that medium skilled labor, which represents the largest share in total employment in any sector studied, plays the most important role in the worker's association preference function. An interesting exception, however, is the sector 'software and related activities', where high skilled labor is almost as important as medium skilled labor in the preference function. Our empirical findings suggest that unions do care about both wages and employment in the bargaining process and that firms operate on the contract curve. Significant differences between East and West Germany in the weights unions put on the employment goal cannot be found using conventional significance levels. Since the bargaining power of East German unions measured by the power parameter $\theta$ turns out to be extremely low we are inclined to conclude that almost monopsonistic labor markets exists at least for some sectors in the East.

Lastly, the study indicates strong evidence for capital-skill complementarities in the German business-related services sector and weak evidence for skill-biased technological change: investment in information technology has a positive and highly significant effect on the demand for high skilled labor, while it has a negative and insignificant effect on the demand for low skilled labor. New technology has a comparatively small and insignificant negative effect on the demand for medium skilled labor.

There are, of course, numerous avenues for further research. We want to point at one interesting extension of the present analysis only. If estimates of a complete model including the product demand curve are available, equilibria of the skill structure of employment and wages can be simulated as a response to technological progress. Such an approach could obviously overcome the drawback of many studies on the technological skill bias based on the assumption that skill specific demand for labor is solely determined by the firms. Krugman's hypothesis of the two sides of the same medal could be tested by an approach encompassing major model specifications. 


\section{Appendix}

Table A1: Descriptive statistics

\begin{tabular}{lrrrrr} 
& \# of obs. & Mean & Std. dev. & Min. & Max. \\
\hline \hline$w_{1 t}$ & 965 & 121.3899 & 31.46886 & 60.65984 & 221.7077 \\
$w_{1 t-1}$ & 924 & 113.0652 & 23.28923 & 70.11449 & 260.4128 \\
$w_{2 t}$ & 965 & 71.92072 & 11.54692 & 38.83521 & 93.2472 \\
$w_{2 t-1}$ & 924 & 70.16949 & 11.97526 & 38.37254 & 101.5699 \\
$w_{3 t}$ & 965 & 57.16722 & 10.3874 & 31.81826 & 76.26497 \\
$w_{3 t-1}$ & 924 & 54.04748 & 9.718782 & 12.04629 & 74.15614 \\
East Germany & 965 & 0.3720207 & 0.4835945 & 0 & 1 \\
CONSULTING & 965 & 0.1108808 & 0.3141473 & 0 & 1 \\
TECHNICAL & 965 & 0.1689119 & 0.3748684 & 0 & 1 \\
OTHER BRS & 965 & 0.1803109 & 0.3846455 & 0 & 1 \\
SEWAGE & 965 & 0.0839378 & 0.2774383 & 0 & 1 \\
CARGO & 965 & 0.2393782 & 0.4269253 & 0 & 1 \\
SOFTWARE & 965 & 0.1295337 & 0.3359638 & 0 & 1 \\
OTHER & 965 & 0.0870466 & 0.2820496 & 0 & 1 \\
$\left(x_{t} / y_{t}\right)^{.5}$ & 920 & 0.0977051 & 0.0893734 & 0 & 0.8451542 \\
$\left(x_{t-1} / y_{t-1}\right)^{.5}$ & 920 & 0.0175252 & 0.0401685 & 0 & 0.7142857 \\
$\left(x_{t} / y_{t}\right)$ & 907 & 0.0972959 & 0.0878026 & 0 & 0.6336522 \\
$\left(x_{t-1} / y_{t-1}\right)$ & 907 & 0.0171673 & 0.0345286 & 0 & 0.4015152
\end{tabular}

Table A1 displays descriptive statistics of the variables involved in the estimations. The subscript $t$ denotes that the corresponding variable is related to 1996. If $t-1$ is indicated, the variable refers to 1995. 


\section{References}

Bean, C.R., Turnbull, P.J., 1988. Employment in the British Coal Industry: A Test of the Labour Demand Model, Economic Journal 98(398), 1092-1104.

Berthold, N., Fehn, R., 1998. Does EMU Promote Labor-Market Reforms?, Kyklos 51(4), 509-536.

Bellmann, L., Kohaut, S., Schnabel, C., 1998. Ausmaß und Entwicklung der übertariflichen Entlohnung, iw-Trends 25(2), 1-10.

Bispinck, R., 1999. Collective Wage Bargaining in Germany 1988/1999, WSI discussion paper No. 76.

Brown, J.N., Ashenfelter, O., 1986. Testing the Efficiency of Employment Contracts, Journal of Political Economy 94(3), S40-S87.

Bughin, J., 1993. Union-Firm Efficient Bargaining and a Test of Oligopolistic Conduct, Review of Economics and Statistics 75(3), 563-567.

Bughin, J., 1996. Trade Unions and Firms' Product Market Power, Journal of Industrial Economics 44(3), 289-307.

Calmfors, L., Driffill, J., 1988. Centralization of Wage Bargaining, Economic Policy 6, $14-61$.

Carrurth, A., Schnabel, C., 1993. The Determination of Contract Wages in West Germany, Scandinavian Journal of Economics 95, 297-310.

Fitzenberger, B., 1999. Heterogeneous Labor in a Structural Empirical Model of Wage Bargaining in West Germany, University of Mannheim discussion paper.

Fitzenberger, B., Haggeney, I., Ernst, M., 1999. Wer ist noch Mitglied in Gewerkschaften?, Zeitschrift für Wirtschafts- und Sozialwissenschaften, 119(2), 223-264.

Fitzenberger, B., Franz, W., 1999. Industry-Level Wage Bargaining: A Partial Rehabilitation - The German Experience, ZEW discussion paper No. 99-33.

Freeman, R.B., 1995. Are Our Wages Set in Bejing?, Journal of Economic Perspectives $9(3), 15-32$.

Janz, N. and G. Licht, 1999. Innovationsaktivitäten der deutschen Wirtschaft. NomosVerlag, Baden-Baden. 
Janz, N., Ebling, G., Gottschalk, S., Peters, B., 2000. The Mannheim Innovation Panel, (MIP): Survey Methodology and Empirical Research, ZEW mimeo, presented at the 9th International Conference on Panel Data at Geneva, June 22-23, 2000.

Kaiser, U., 2000a. The Impact of Foreign Competition and New Technologies on the Demand for Heterogeneous Labor, ZEW discussion paper No. 98-26, forthcoming in: Review of Industrial Organization.

Kaiser, U., 2000b. New Technologies and the Demand for Heterogeneous Labor: Firmlevel Evidence for German Business-related Services, ZEW discussion paper No. 99-07, forthcoming in: Economics of Innovation and New Technology.

Kaiser, U., 2000c. A Note on the Calculation of Firm-Specific and Skill-Specific Labor Cost from Firm-Level Data, ZEW discussion paper No. 00-08.

Kaiser, U., Kreuter, M., Niggemann, H., 2000. Calculating Expansion Factors for a Business Survey in the Business-Related Services Sector, ZEW discussion paper $00-22$.

Kaiser, U., Pfeiffer, F., 2000. Collective Wage Agreements, Workers and Hours Adjustment: Evidence from a panel of German service firms, ZEW discussion paper $00-33$.

Klotz, S., Pfeiffer, F., Pohlmeier, W., 1999. Zur Wirkung des technischen Fortschritts auf die Qualifikationsstruktur der Beschäftigung und die Entlohnung, Jahrbücher für Nationalökonomie und Statistik 219, 90-108.

Layard, S., Nickell, S., 1999. Labor Market Institutions and Economic Performance. In: O. Ashenfelter, Card, D. (Eds.) Handbook of Labor Economics, Vol. 3. NorthHolland, Amsterdam.

Licht, G., Hipp, C., Kukuk, M., Münt, G., 1997. Innovationen im Dienstleistungssektor. Nomos-Verlag, Baden-Baden.

MaCurdy, T.E., Pencavel, J.H., 1986. Testing Between Alternative Models of Wage and Employment Determination in Unionized Markets, Journal of Political Economy 94(3), S3-S39.

Manning, A., 1987. An Integration of Trade Union Models in a Sequential Bargaining Framework, Economic Journal 97, 121-139.

Martinello, F., 1989. Wage and Employment Determination in a Unionized Industry: The IWA and the British Columbia Wood Products Industry, Journal of Labor Economics 7, 303-330. 
McDonald, I.M., Solow, R.M., 1981.Wage Bargaining and Employment, American Economic Review 71, 896-908.

Miles, I., 1993. Services in the New Industrial Economy, Futures, 653-672.

McDonald, I.M., Solow, R.M., 1981. Wage Bargaining and Employment, American Economic Review 71, 896-908.

Morrison, C.J., 1988. Quasi-fixed Inputs in U.S. and Japanese Manufacturing: A Generalized Leontief Restricted Cost Function Approach, The Review of Economics and Statistics 70(2), 275-287.

Oswald, A.J., 1993. Efficient Contracts are on the Labour Demand Curve - Theory and Facts, Labour Economics 1(1), 85-113.

Pencavel, J., Holmlund, B., 1988. The Determination of Wages and Employment in an Economy with Centralized Wage-Setting, Economic Journal 98, 1105-1126.

Pfeiffer, F., Falk, M., 1999. Der Faktor Humankapital in der Volkswirtschaft. Berufliche Spezialisierung und technologische Leistungsfähigkeit, ZEW-Wirtschaftsanalysen, Vol. 35, Nomos Verlagsgesellschaft, Baden-Baden.

Scheremet, W., 1995. Tarifpolitik in Ostdeutschland: Ausstieg aus dem Lohnverhandlungsmodell der Bundesrepublik Deutschland? Beihefte der Konjunkturpolitik, Zeitschrift für angewandte Wirtschaftsforschung 114, 135-169.

Siebert, H., 1997. Labor Market Rigidities: At the Root of Unemployment in Europe, Journal of Economic Perspectives 11(3), 37-54.

Statistisches Bundesamt, 1995a. Kostenstruktur des gewerblichen Güterkraftverkehrs, der Speditionen und Lagereien, der Binnenschiffahrt, Güterbeförderung) und der See-- und Küstenschiffahrt, Stuttgart: Metzler-Poeschel.

Statistisches Bundesamt, 1995b. Kostenstruktur bei Rechtsanwälten und Anwaltshonoraren, bei Wirtschaftsprüfern vereidigten Buchprüfern, Steuerberatern und Steuerbevollmächtigten, bei Architekten und Beratenden Ingenieuren, Stuttgart: MetzlerPoeschel.

Statistisches Bundesamt, 1995c. Kostenstruktur der Unternehmen der Wirtschaftsund Unternehmensberatung sowie der Heilpraktikerpraxen, Stuttgart: MetzlerPoeschel.

Statistisches Bundesamt, 1995d. Kostenstruktur der Unternehmen des Verarbeitenden Gewerbes sowie des Bergbaus und der Gewinnung von Steinen und Erden, Stuttgart: Metzler-Poeschel. 